\title{
Technologies and Emergency Management for Disaster Recovery With Focus on the Great East Japan Earthquake
}

\author{
Kazuhiko KINOSHITA $^{\dagger a)}$, Member, Yukio ITO $^{\dagger \dagger}$, Nonmember, Hideaki KIMURA ${ }^{\dagger \dagger \dagger}$, \\ and Yuji MAEDA ${ }^{\dagger+\dagger}$, Members
}

SUMMARY This letter summarizes three talks in the tutorial session of the 13th Asia-Pacific Network Operations and Management Symposium (APNOMS2011), which focused on the disaster recovery and further emergency management regarding the Great East Japan Earthquake of 2011. We present the damage and restoration of communication networks and points to a future disaster-resilient society.

key words: disaster recovery, emergency management, earthquake

\section{Introduction}

In 2011, a great earthquake with a magnitude of 9.0 struck eastern Japan and led to a tremendous $15-40 \mathrm{~m}$ tsunami. The Great East Japan Earthquake and tsunami killed more than 15,000 people and created over 300,000 refugees [1]. Communication infrastructures were also significantly damaged [2].

We have conducted research and development of various technologies that minimize the effects of earthquakes to communication services. In addition, after this earthquake, which was an immense disaster, we recognize again that communication is very important as a lifeline service, along with electricity, water, and gas services.

This letter introduces the damage and restoration of backbone networks and access networks in Sect. 2 and Sect. 3, respectively. Moreover, a future ideal disasterresilient society is indicated in Sect. 4.

\section{Backbone Networks}

\subsection{Domestic Communications}

As for regional communications facilities, many telecom buildings and facilities were damaged, e.g. snapped cables, pipe, domestic/international cables, etc. In addition, a prolonged commercial power interruption caused a complete outage of the UPS, resulting in further damage: 90 routes

Manuscript received December 28, 2011.

Manuscript revised February 13, 2012. Japan.

${ }^{\dagger}$ The author is with Osaka University, Suita-shi, 565-0871

${ }_{\dagger \dagger}$ The author is with NTT Communications, Tokyo, 100-8019 Japan

${ }^{\dagger \dagger}$ The author is with NTT Access Network Services Syestems Labs., NTT Corporation, Tsukuba-shi, 305-0805 Japan.

${ }^{\dagger+}+$ The author is with NTT Service Integration Labs., NTT Corporation, Musashino-shi, 180-8585 Japan.

a) E-mail: kazuhiko@ist.osaka-u.ac.jp

DOI: 10.1587/transcom.E95.B.1911 were demolished; 18 buildings were totally destroyed and a further 23 were flooded; $6,000 \mathrm{~km}$ of aerial cable was swept away or demolished in coastal regions; and 65,000 telephone poles were swept away or badly damaged.

Fortunately, domestic transmission stations suffered no serious damage, and no blackouts affected them, with continuous power being supplied by the UPS and emergency power generators. In addition, as a backup, mobile generator trucks were ready for deployment.

Multiple diversified transmission routes were constructed to achieve immediate restoration by the following procedures as shown in Fig. 1.

1. After installing the additional route, switching from the primary to the secondary was achieved without interruption.

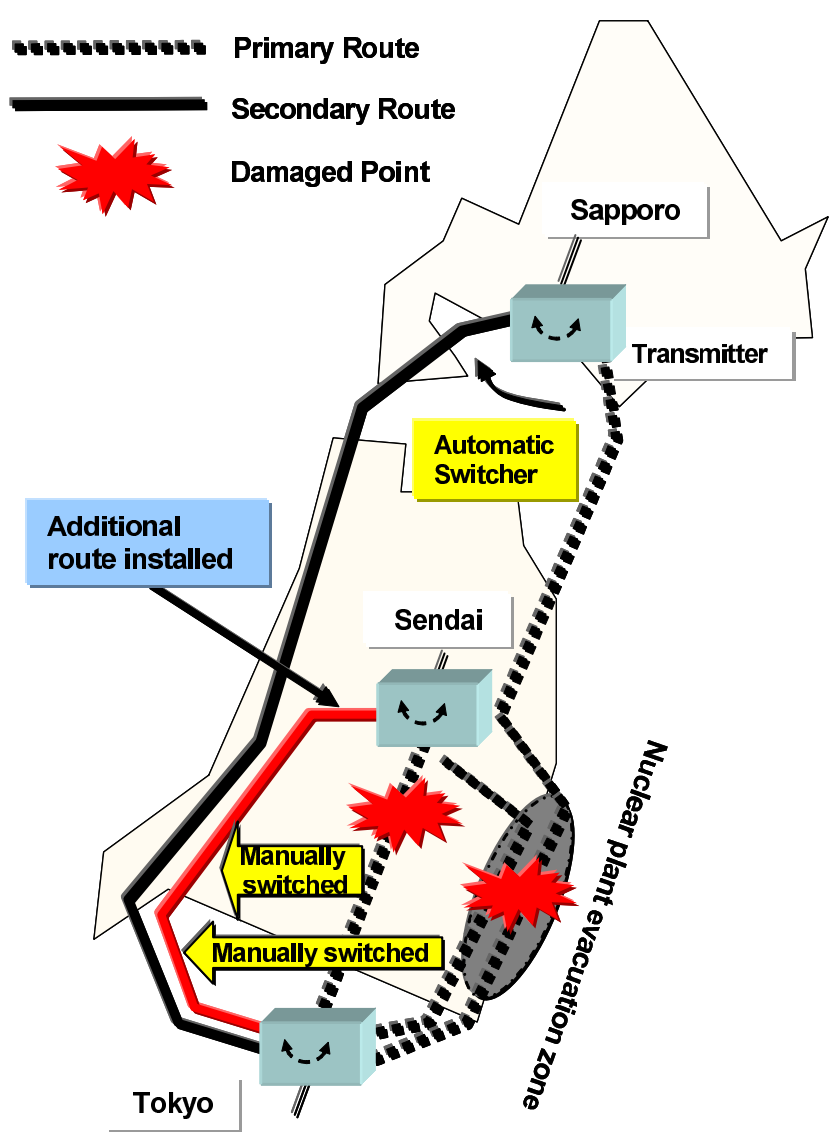

Fig. 1 Multiple number of diversified transmission routes. 
2. The tentative restoration of the transmission network cables enabled the reestablishment of the service, and also provided network redundancy.

The disaster-stricken transmission network cables were restored by connection work, installation of detour routes, route-switching work, and so on. The first-aid restorations were completed in two days, as follows.

March 11 The earthquake happened, and some cables had been cut.

March 12 Moved by helicopter to Miyagi Prefecture, to identify the fault points and assigned the local engineers to work.

March 13 Restoration work was carried out. The point where the cable was cut off was identified and 27 sets of telephone poles were arranged to deploy the detour route. The rerouted cable was $1 \mathrm{~km}$ long. To connect the cables from a manhole to a pole, a tentative conduit was made.

April 26 Traffic was fully restored to the level before the earthquake.

Restoration of the IP backbone network was completed by rerouting to the nonaffected route and service was restored on March 11, and a redundancy route became available on April 6.

\subsection{International Communications}

Despite many undersea routes between Japan and the USA being affected, restoration by rerouting to alternative cable routes secured availability of international data and Internet services. The landing stations function was kept, and this minimized the effects of the damage to the undersea cables.

When the undersea cable off the coast of Ibaraki was disconnected, traffic was automatically rerouted to another landing station and traffic-increased circuit facilities were enhanced accordingly.

\subsection{Future Work}

For a disaster-proof network and quick disaster recovery, decentralization of important functions and pluralized routes are necessary. The three-route redundancy is efficient. Measures for wide-area, long-term power outages are also essential. For the quick recovery of communications at regional hub POPs, the wireless network, including satellite communications, may be effective. For ensuring information distribution measure after disasters, users require congestion avoidance in both telecommunication and IP networks to assure safety immediately following a disaster.

\section{Access Network}

\subsection{Damage and Restoration}

The problems caused by the quake to the access network were as follows.

1. Network infrastructure

a. Congestion of telephones (mobile and fixed)

b. Blackouts causing a halt to telephone communication systems

c. Backup power failing after the blackout

d. Destruction and flooding of communication equipment by the tsunami

\section{Services}

a. Blackouts halting telephone services and destruction of congestion regulation

b. Email services stopping due to blackouts affecting infrastructure

c. The earthquake warning system could not be implemented because terminals such as smart phones lost reception

d. Destruction of information distribution systems, and loss of important data due to damage and disappearance of the family registers, resident information, etc., in local government repositories

To achieve a high reliability of the network, the network is designed in such a way to decentralize important communication centers and the relay transmission line is multiroute. Around-the-clock network monitoring has been introduced, and the cable tunnel, building, and wireless iron tower are designed to endure a large earthquake.

To secure delivery of important communications, safety information is provided by the voice mail service for disaster (171), the i-mode mail service for disaster (web171), and by setting up special and temporary public telephones and opening of the street public telephones.

Restoration of service at an early stage is also important. A temporary telephone office will be constructed by transporting about 10 portable digital switchboards. Satellite-based restoration of communication is also ready.

The access infrastructure, including equipment such as conduits, cable tunnels and manholes, was constructed in Japan after 1950. Access infrastructure that accommodates and protects communications cable such as metallic and optical fiber is shown in this figure.

\subsection{Countermeasures}

Increased flexibility and lower cost are the keys for quakeresistant enhancement technologies for basic equipment. Moreover, it is important to set technology priorities considering the level of equipment deterioration. The use of an equipment database will assist recruitment of workers and access to funds. On the other hand, from the network point of view, to improve the reliability and maintenance capability of the Ethernet carrier network, we developed the following three technologies as shown in Fig. 2 and a new operation system; (i) We improve the maintenance and operation capability by proactive monitoring, fault verification 


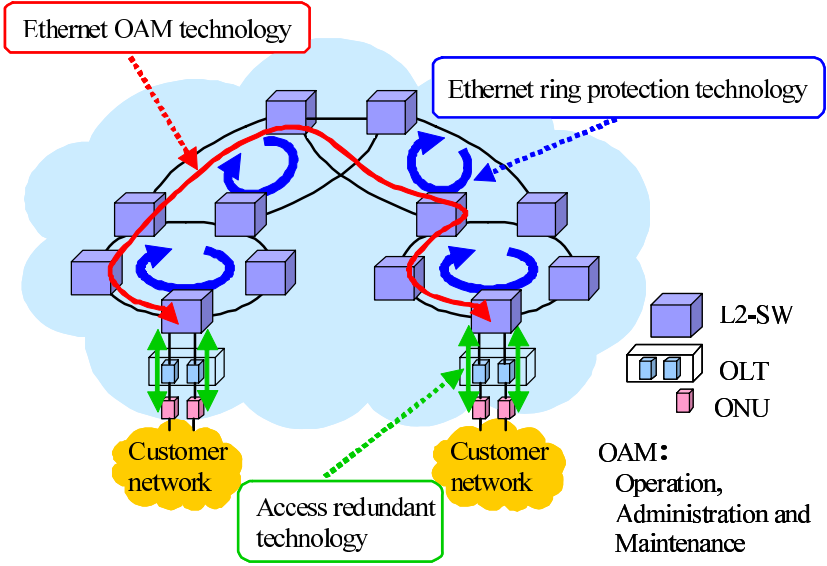

Fig. 2 Wide area ethernet service.

and performance measurement on each VLAN. (ii) We enhance the reliablity by loop-free, rapid protection switching on ring-based network [3]. (iii) We improve the reliability by access line duplication and rapid protection switching under failure condition.

In addition, to expand the covered area, we developed an optical amplifying PON (Passive Optical Network) repeater that can extend the area the FTTH provided (longreach/high-split-ratio) by amplifying the optical signal of the PON system between Optical Line Terminal (OLT) and Optical Network Units (ONUs) [4]. Because it does not rely on the bit rate/protocol, it can be used in various PON systems. We also promote area expansion and create new services with the wireless technology named "personal wireless router" (PWR). PWR selects the best network to connect to and subscribes user devices to the Internet automatically. An automatic data-gathering service for "items" such as home electronics, cars and vending machines would also be provided in a wide-area ubiquitous network.

\section{Emergency Management in a Disaster-Resilient So- ciety}

\subsection{Incident Response by Governments}

A disaster headquarters and headquarters in disaster areas were established for the first time by the national government. The widespread disaster and operation from several headquarters led to overcomplexity of the government system and an increase in clerical work. Therefore, the government's regional coordination was not smooth. Moreover, the government's emergency response was not quick enough.

On the other hand, based on previous disaster experiences, local governments were prepared for many issues (earthquake resistance of buildings, initial response, and framework for cooperation, etc.). Cooperation from distant local governments worked well. However, because of the severity of the disaster, it took a long time to build temporary housing, issue certification to disaster victims, and handle monetary donations. The number of evacuees and in temporary housing was 82,634 and 50,982, respectively, on August 23, 2011.

Regarding lifeline companies, electric power was restored quickly, except for nuclear power station (NPS) sites. Response at NPS sites could not be evaluated. Town gas was restored quickly because of the support of about 10,000 workers from 59 companies from around the country. Water was also restored quickly through cooperation with distant local governments.

To prepare for critical incidents such as typhoons, heavy rains, tornadoes, nuclear incidents, terror, cyber terror, and new strains of pandemics, it is important to become resilient. When a disaster or crisis occurs, we must restore services as soon as possible based on countermeasures, using hardware (buildings, facilities, etc.) and software organization systems (ICT systems, education, drills, etc.).

\subsection{Resilient Society}

A resilient society is a society that is resistant against and resilient in disasters and crises. It requires an autonomous decentralized society, bringing together autonomous individuals acting and working across the region: for example, selfhelp, public help, and community help. A resilient society is an autonomous and decentralized one that leverages distributed collaborative ICT systems to achieve a high degree of resilience in dealing with disasters and crises. It requires precise and appropriate information, maintenance processes and organization, and appropriate use of ICT systems such as cloud computing, large-capacity backup power supplies, standardization of operations (workflow, format of reporting and data), and standardization of the application interface of ICT services.

The Incident Command System (ICS) was constructed as a remedy for the problems faced by emergency managers fighting with wildfires in the Californian forests in the early 1970s. The ICS is a standardized emergency management system that coordinates multiagency activities for managing rapidly moving wildfires. Because of its success in the Californian wildfires, the ICS has evolved into a national program, not only for wildfires, but also for all kinds of incidents in the United States since the 1980s. It is fair to say that the ICS has become a de facto global standard for emergency management.

All ICS organizations have the following five major functions: command, operation, planning, logistics and finance/administration. In addition, an ICS organization can best be described with the following nine features: modular organization, common terminology, designated incident facilities, unified command structure, unity of command, control span, operational period, unit log and consolidated Incident Action Plan. Figure 3 shows the continual plannning process in the motif of " $P$ ".

ICS concept is standardized in ISO 22320. ISO22320 defines the standard for societal security, emergency management, and requirements for command and control. This standard specifies requirements for command and control, 


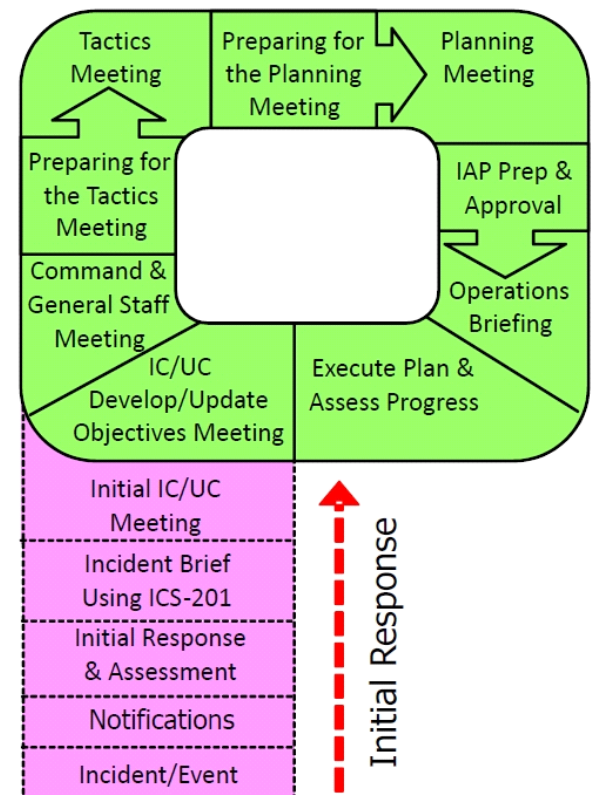

Fig. 3 Operational planning "P".

information, coordination and cooperation that provide the basis for effective command and control within the incident response organization. They include the command and control of organizational structures and procedures, decision support, traceability, information management, and interoperability within incident response organizations. This document also establishes requirements for operational information for emergency management, which define processes, systems of work, and data capture and management, to produce timely, relevant, and accurate information. This document is applicable to any organization - private, public, governmental or nonprofit - involved in the preparation for or response to incidents on an international, national, regional or local level. ISO22320 was standardized in the fall of 2011

\section{Conclusions}

We are proud to say that we have developed and applied the best quake- and tsunami-resistance technologies, which again proved their effectiveness during the 2011 Japan earthquake. We are, and will continuously be, working for further improvement by investigating the 2011 quake and future quakes. At the same time, we have learned the importance of collaborating with the government and local communities in realizing disaster-resistant communications and networks, because a truly strong, resilient and still costeffective city requires good city planning.

As a final remark, this huge quake and tsunami has had a crucial effect on our society because of the destruction of the Fukushima-Daiichi reactors, which resulted in radiation leaks, rumors, economic impact, and an effect on our mindset. We are now reinventing our society, but it will take years or tens of years to heal the scars to our minds.

\section{References}

[1] M. Hosokawa, "The disaster caused by the 2011 Great East Japan Earthquake and fire fighting operation by Japanese fire service," IEICE Commun. Society Global News Lett., vol.35, no.4, pp.7-8, Dec. 2011.

[2] Y. Ito, H. Kimura, and Y. Maeda, "Disaster recovery - Focused on the earthquake in Japan," Proc. 13th Asia Pacific Network Operations and Management Symposium (APNOMS 2011), Tutorial Session, Sept. 2011.

[3] Ethernet Ring Protection Switching, ITU-T Rec. G.8032/Y.1344, 2010.

[4] R.P. Davey, B. Grossman, M. Rasztovits-Wiech, D.B. Payne, D. Nesset, A.E. Kelly, A. Rafel, S. Appathurai, and S. Yang, "Longreach passive optical networks," J. Lightwave Technol., vol.27, no.3, pp.273-291, 2009.

[5] Y. Maeda, M. Higashida, K. Iwatsuki, T. Handa, Y. Kiriha, and H. Hayashi, "Next generation ICT services underlying the resilient society," J. Disaster Research, vol.5, no.6, pp.627-635, Dec. 2010. 